\title{
Detection of NPMI exon I 2 mutations and FLT3 - internal tandem duplications by high resolution melting analysis in normal karyotype acute myeloid leukemia
}

\author{
Angela YC Tan ${ }^{1}$, David A Westerman ${ }^{1,2,3}$, Dennis A Carney2, \\ John F Seymour ${ }^{2}$, Surender Juneja ${ }^{4}$ and Alexander Dobrovic*1,3
}

Address: ${ }^{1}$ Department of Pathology, Peter MacCallum Cancer Centre, Melbourne, Australia, ${ }^{2}$ Department of Haematology and Medical Oncology, Peter MacCallum Cancer Centre, Melbourne, Australia, ${ }^{3}$ Department of Pathology, University of Melbourne, Parkville, Australia and ${ }^{4}$ Royal Melbourne Hospital, Parkville, Australia

Email: Angela YC Tan - angela.tan@petermac.org; David A Westerman - david.westerman@petermac.org;

Dennis A Carney - dennis.carney@petermac.org; John F Seymour - john.seymour@petermac.org; Surender Juneja - surender.juneja@mh.org.au; Alexander Dobrovic* - alexander.dobrovic@petermac.org

* Corresponding author

Published: 29 July 2008

Journal of Hematology \& Oncology 2008, I:10 doi: 10.1 I86/I756-8722-I-10

This article is available from: http://www.jhoonline.org/content/l/I/10

(c) 2008 Tan et al; licensee BioMed Central Ltd.

This is an Open Access article distributed under the terms of the Creative Commons Attribution License (http://creativecommons.org/licenses/by/2.0), which permits unrestricted use, distribution, and reproduction in any medium, provided the original work is properly cited.
Received: 20 May 2008

Accepted: 29 July 2008

\begin{abstract}
Background: Molecular characterisation of normal karyotype acute myeloid leukemia (NK-AML) allows prognostic stratification and potentially can alter treatment choices and pathways. Approximately $45-60 \%$ of patients with NK-AML carry NPMI gene mutations and are associated with a favourable clinical outcome when FLT3-internal tandem duplications (ITD) are absent. High resolution melting (HRM) is a novel screening method that enables rapid identification of mutation positive DNA samples.
\end{abstract}

Results: We developed HRM assays to detect NPMI mutations and FLT3-ITD and tested diagnostic samples from 44 NK-AML patients. Eight were NPMI mutation positive only, 4 were both NPMI mutation and FLT3-ITD positive and 4 were FLT3-ITD positive only. A novel point mutation $Y 572 C$ (c. I7I5A>G) in exon 14 of FLT3 was also detected. In the group with de novo NKAML, $40 \%$ (I2/29) were NPMI mutation positive whereas NPMI mutations were observed in $20 \%$ $(3 / 15)$ of secondary NK-AML cases. Sequencing was performed and demonstrated $100 \%$ concordance with the HRM results.

Conclusion: HRM is a rapid and efficient method of screening NK-AML samples for both novel and known NPMI and FLT3 mutations. NPMI mutations can be observed in both primary and secondary NK-AML cases.

\section{Background}

Acute myeloid leukemia with a normal karyotype (NK$\mathrm{AML}$ ) is considered to have an intermediate prognostic risk with 5 year disease free survival (DFS) ranging between $24-42 \%[1,2]$. However, there is marked varia- bility in outcome suggesting significant biological and molecular heterogeneity within this group of AML [3].

In 2005, Falini et al. described a set of common mutations within the final exon of the NPM1 gene in primary NK- 
AML patients, which alter the N-terminal domain nuclear localisation signal leading to abnormal cytoplasmic accumulation of the NPM1 phosphoprotein [4]. While the precise functional effect of the NPM1 mutation is incompletely understood, several groups confirmed that NKAML patients have a high incidence of NPM1 exon 12 mutations ( 24\% - 60\%) [5-9]. Mutations in NPM1 are the most frequent genetic change known in patients with NK-AML and a number of studies have shown that NPM1 mutation positive patients have a better prognosis with longer event-free and overall survival (OS) [10].

Schnittger et al. demonstrated that the favourable prognostic implications of NPM1 mutation status are overridden in FLT3-ITD positive cases which have a uniformly poor prognosis [7]. These findings demonstrate the need to screen patients for mutations in FLT3-ITD alongside NPM1 [10]. However, such a molecular screening program can be demanding on the resources of a diagnostic laboratory. Therefore, in this study we assessed the use of high resolution melting (HRM) analysis as a rapid method to screen NK-AML patient samples for the critical molecular changes in NPM1 and FLT3.

\section{Results and Discussion}

In this study, we developed HRM assays allowing rapid assessment of the mutation status of NPM1 and the presence of the FLT3-ITD in the same run. In HRM, the PCR product is subjected to melting in the presence of a dye that only fluoresces when bound to double stranded DNA [11]. As melting is sequence dependent, monitoring the precise melting behaviour by observing the change in fluorescence allows the detection of variant sequences. In addition, sequence variants in the DNA such as mutations give rise to heteroduplexes that form earlier melting products allowing ready detection of mutations even at comparatively low concentrations.

Samples from 44 patients with NK-AML were analysed. The median age of the patients was 62 years (range 18-89 years) and $27(61 \%)$ patients were male. Twenty nine (66\%) had de novo AML and 15 (34\%) had secondary AML. Sixteen patients generated an abnormal melting
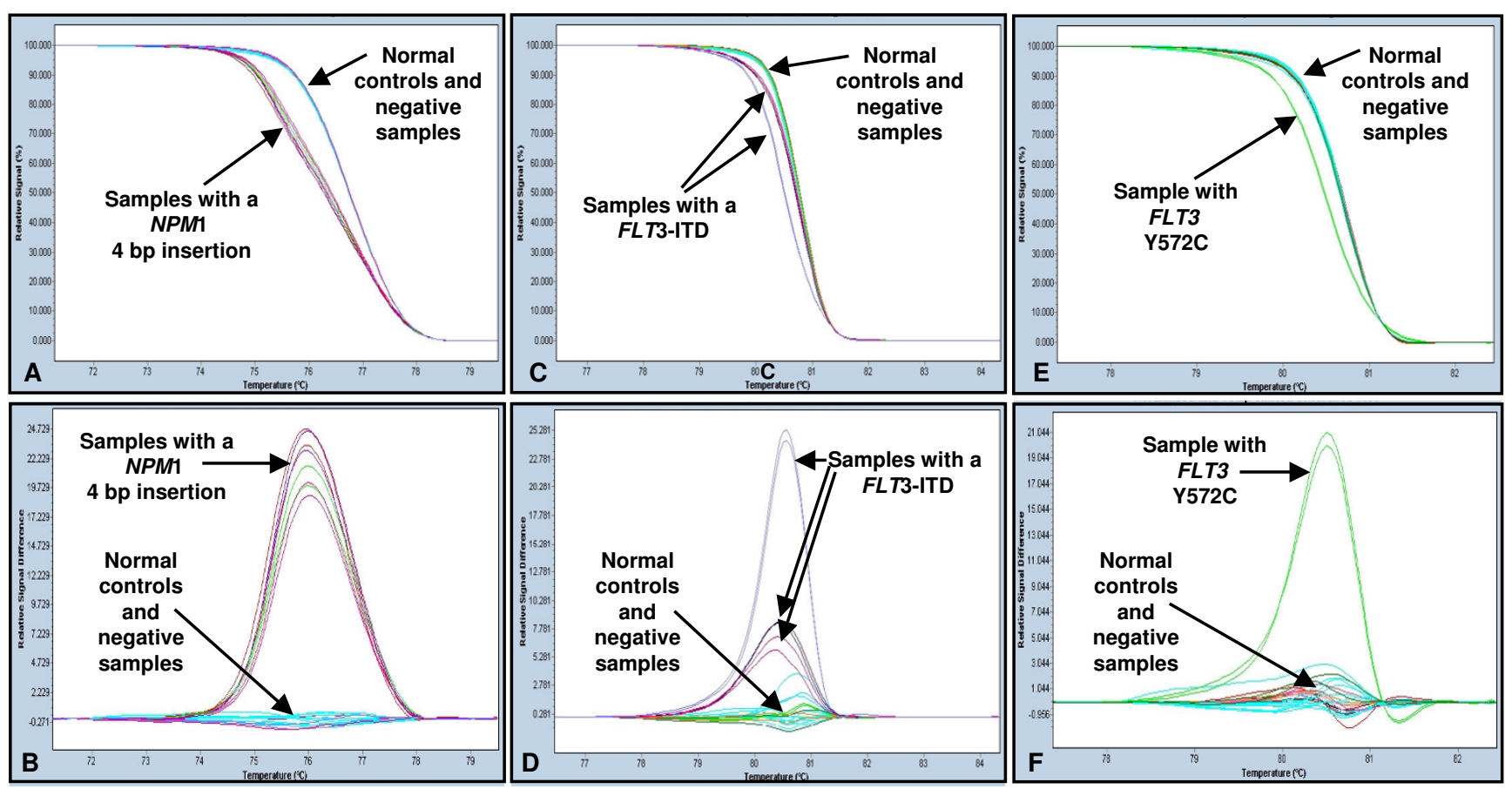

Figure I

Detection of NPMI mutations and FLT3-ITD using high resolution melting analysis. (A) The melt curve of NPM I exon 12 and (B) The difference plot of NPMI exon 12. Six patient samples are shown in comparison to five normal controls. Four patients (\#6, \#I2, \#I4 and \#38) are NPMI mutation positive and two patients (\#33 and \#43) are NPMI mutation negative. (C) The melt curve of FLT3 exon I4 and (D) The difference plot of FLT3 exon I4 - Six patient samples are shown in comparison to five normal controls. Three patients (\#6, \#33 and \#43) are FLT3-ITD positive and three patients (\#I2, \#I4 and \#48) are FLT3-ITD negative. (E) The melt curve of FLT3 exon I4 and (F) The difference plot of FLT3 exon I4 - Eight patient samples are shown in comparison to five normal controls. One patient (\#19) is positive for FLT3 Y572C and seven patients (\#4, \#5, $\# 10, \# 24, \# 25$, \#26 and \#30) are FLT3 mutation negative. All samples are shown in duplicate. 
Table I: Patient demographics and list of NPMI and FLT3-ITD mutations detected

\begin{tabular}{|c|c|c|c|c|c|c|c|c|}
\hline$\#$ & Age & Sex* & $\mathrm{FAB}$ & Prior Disease & HRM - NPMI & Seq-NPMI§ & $\begin{array}{c}\text { HRM - FLT3- } \\
\text { ITD }\end{array}$ & Seq-FLT3-ITD| \\
\hline I & 64 & $M$ & MI & Nil & Normal & Neg & Normal & Neg \\
\hline 2 & 63 & $M$ & M6 & MDS & Normal & $\mathrm{Neg}$ & Normal & $\mathrm{Neg}$ \\
\hline 3 & 36 & $M$ & M2 & Nil & Normal & Neg & Normal & $\mathrm{Neg}$ \\
\hline 4 & 69 & $M$ & basophilic leukemia & RAEB-T & Normal & $\mathrm{Neg}$ & Normal & Neg \\
\hline 5 & 68 & $M$ & M2 & Nil & Normal & $\mathrm{Neg}$ & Normal & $\mathrm{Neg}$ \\
\hline 6 & 81 & $M$ & M5 & Nil & Aberrant & 860_863dupTCTG & Aberrant & 1754_I798dup \\
\hline 7 & 19 & $M$ & M2 & Nil & Normal & Neg & Normal & Neg \\
\hline 8 & 68 & $M$ & M6 & Nil & Normal & Neg & Normal & Neg \\
\hline 9 & 72 & $M$ & M4 & CMML & Normal & $\mathrm{Neg}$ & Normal & $\mathrm{Neg}$ \\
\hline 10 & 58 & $\mathrm{~F}$ & M2 & $\mathrm{Nil}$ & Aberrant & 860_863dupTCTG & Normal & $\mathrm{Neg}$ \\
\hline 11 & 66 & $\mathrm{~F}$ & $M 4 / 5$ & MDS transformed & Aberrant & 860_863dupTCTG & Normal & Neg \\
\hline 12 & 51 & $\mathrm{~F}$ & M4 & Nil & Aberrant & 860_863dupTCTG & Normal & Neg \\
\hline 13 & 42 & $\mathrm{~F}$ & $M 2$ & MDS/pelvic chloroma & Normal & Neg & Normal & Neg \\
\hline 14 & 53 & $M$ & M4 & Nil & Aberrant & 860_863dupTCTG & Normal & Neg \\
\hline 15 & 59 & $\mathrm{~F}$ & MI & $\mathrm{Nil}$ & Aberrant & 860_863dupTCTG & Aberrant & $\begin{array}{l}\text { 1811_1837dup } \\
\text { 1838_I867ins }\end{array}$ \\
\hline 16 & 69 & $M$ & MI & Nil & Normal & Neg & Normal & $\overline{N e g}$ \\
\hline 17 & 52 & $M$ & MI & MDS & Normal & Neg & Normal & Neg \\
\hline 18 & 74 & $M$ & MI & Nil & Normal & $\mathrm{Neg}$ & Normal & $\mathrm{Neg}$ \\
\hline 19 & 66 & $M$ & MO & ca prostate & Aberrant & 860_863dupTCTG & Aberrant & $1715 A>G$ \\
\hline 20 & 52 & $M$ & MI & MDS & Normal & Neg & Normal & Neg \\
\hline 21 & 75 & $M$ & MI & MDS & Normal & Neg & Normal & Neg \\
\hline 22 & 56 & $M$ & MO & NHL on $\mathrm{TX}$ & Normal & Neg & Normal & Neg \\
\hline 23 & 18 & $\mathrm{~F}$ & MI & Nil & Normal & Neg & Normal & Neg \\
\hline 24 & 73 & $M$ & M4 & Nil & Normal & Neg & Normal & Neg \\
\hline 25 & 56 & $\mathrm{~F}$ & MI & therapy related & Normal & Neg & Normal & Neg \\
\hline 26 & 53 & $\mathrm{~F}$ & M4 & Nil & Aberrant & 860_863dupTCTG & Normal & Neg \\
\hline 27 & 64 & $M$ & MO & MDS & Normal & Neg & Normal & Neg \\
\hline 28 & 63 & $\mathrm{~F}$ & M5a & Nil & Aberrant & 86I_864insCTGC & Normal & Neg \\
\hline 29 & 71 & $\mathrm{~F}$ & M5b & MDS transformed & Aberrant & 860_863dupTCTG & Aberrant & 1754_I789dup \\
\hline 30 & 89 & $\mathrm{~F}$ & M6 & Nil & Normal & Neg & Normal & Neg \\
\hline 31 & 28 & $\mathrm{~F}$ & M4 & $\mathrm{Nil}$ & Normal & Neg & Normal & Neg \\
\hline 32 & 69 & $\mathrm{~F}$ & basophilic leukemia & Nil & Normal & Neg & Normal & Neg \\
\hline 33 & 36 & $\mathrm{~F}$ & M5b & Nil & Normal & $\mathrm{Neg}$ & Aberrant & 1783_1812dup \\
\hline 34 & 54 & $M$ & MI & $\mathrm{Nil}$ & Normal & Neg & Normal & Neg \\
\hline 35 & 52 & $M$ & MI & $\mathrm{Nil}$ & Normal & Neg & Normal & Neg \\
\hline 36 & 82 & $M$ & M4 & Nil & Normal & $\mathrm{Neg}$ & Aberrant & |786G $>$ C 1787_|818dup \\
\hline 37 & 68 & $M$ & M5b & CMML & Normal & Neg & Normal & Neg \\
\hline 38 & 61 & $\mathrm{~F}$ & M4 & Nil & Aberrant & 860_863dupTCTG & Normal & Neg \\
\hline 39 & 49 & $M$ & M4 & $\mathrm{Nil}$ & Normal & Neg & Aberrant & ins? bp Tl \\
\hline 40 & 83 & $\mathrm{~F}$ & MI & Nil & Aberrant & 860_863dupTCTG & Normal & Neg \\
\hline 41 & 72 & $\mathrm{~F}$ & M4 & CMML & Normal & Neg & Normal & $\mathrm{Neg}$ \\
\hline 42 & 57 & $M$ & M4 & Nil & Normal & Neg & Normal & Neg \\
\hline 43 & 42 & $M$ & MI & $\mathrm{Nil}$ & Normal & $\mathrm{Neg}$ & Aberrant & $\begin{array}{l}\text { 1741_I83Idup } \\
\text { |832_I842ins }\end{array}$ \\
\hline 44 & 49 & $M$ & M6 & Nil & Normal & Neg & Normal & Neg \\
\hline
\end{tabular}

† MDS = myelodysplastic syndrome; RAEB-T = refractory anemia with excess of blasts in transformation; $\mathrm{CMML}=$ chronic myelomonocytic leukemia; $\mathrm{Ca}$ prostate $=$ prostate cancer; $\mathrm{NHL}=$ Non-Hodgkin lymphoma.

$\ddagger$ Normal $=$ normal melt profile, Aberrant $=$ abnormal melt profile.

$\S \mathrm{Neg}=$ no mutation detected in the sequence; numbering according to NPM/ reference sequence NM_002520.5

| Numbering according to FLT3 reference sequence NM_004 | 19.2 (5'UTR not included)

Tा The size of the internal tandem duplication could not be determined due to the low levels of mutant peaks in the sequence,

profile in one of the two tested amplicons, 8 were NPM1 mutation positive only, 4 were NPM1 positive and FLT3ITD positive and 4 were FLT3-ITD positive only (Figure 1.).
Sequencing confirmed all the HRM detected mutations and did not reveal any further mutations, indicating that HRM was capable of detecting mutations with $100 \%$ sensitivity in this cohort. 
All the NPM1 mutations detected involved one of two 4 base insertions that altered the tryptophan at amino acid position 288 and the FLT3-ITD ranged from 33-102 bases (Table 1). These mutations were similar to those previously described $[4,12,13]$. All 12 NPM1 mutation positive patients were also positive by immunohistochemistry (IHC) on bone marrow trephine sections, showing typical cytoplasmic localisation (data not shown).

The incidence of NPM1 mutations in the de novo AML cases was $40 \%(12 / 29)$, consistent with the incidence reported in previous studies [5-9]. Interestingly, 3/15 of the secondary AML cases were NPM1 mutation positive which contrasts with an earlier study, where cytoplasmic localisation of NPM indicative of NPM1 mutations was not seen in 135 secondary AML samples by IHC [4].

A novel point mutation Y572C in exon 14 of FLT3 was also detected. This tyrosine residue within the juxtamembrane domain of FLT3 has been shown to be phosphorylated in vivo [14] and could be included in the newly described class of FLT3 juxtamembrane domain point mutations for which the similar mutation Y591C has been reported [15]. This illustrates the power of HRM to detect novel as well known mutations. The use of HRM to screen for FLT3-ITD has been previously reported [16].

HRM is rapidly becoming the most important mutation scanning methodology. It is an in-tube method, meaning that PCR amplification and subsequent analysis are sequentially performed in the one tube or well. This makes it more convenient than other scanning methodologies such as denaturing high-performance liquid chromatography [17]. We used a real-time PCR machine with HRM capability rather than a stand-alone HRM instrument. This facilitates quality control as the success of the amplification can be assessed on the same platform as the melting analysis.

HRM has no real disadvantages in mutation scanning except that extra care needs to be taken in designing PCR reactions to avoid primer dimers and non-specific amplification. Secondly, DNA needs to be prepared in a uniform fashion to avoid variation in salt concentration that will affect the melting. In addition, the exact nature of any mutation cannot be determined without sequencing. Nevertheless, performing HRM as an initial screen for potential mutations significantly reduces the volume of samples requiring sequencing with consequent reduction of cost and labour, and improvements to turn around time.

\section{Conclusion}

HRM is likely to play a major role in clinical applications as it enables rapid detection of defined and novel molec- ular changes in clinical samples. In this study, the conditions have been optimised to enable screening of normal karyotype AML patients for both NPM1 and FLT3-ITD in the same run. This has enhanced patient prognostication and clinical decision making regarding therapeutic approaches. The assays are suitable both for individual patient diagnosis and for large scale clinical trials.

\section{Methods}

\section{Patients and samples}

DNA was extracted from archival bone marrow smears from 44 NK-AML patients from 1999-2007 sent to the Pathology Department of The Peter MacCallum Cancer Centre. Normal peripheral blood samples were obtained from 11 healthy volunteers. All samples were collected and were obtained in accordance with the Peter MacCallum Cancer Centre Ethics of Human Research guidelines. DNA was extracted from bone marrow smears using a standard phenol/chloroform extraction technique. DNA was extracted from peripheral blood using the Wizard Genomic DNA Purification Kit (Promega, Madison, WI).

\section{High resolution melting analysis}

The PCR and melting analysis for NPM1 and FLT3 mutations were all performed on the LightCycler 480 (Roche Diagnostics, Penzberg, Germany) a real-time PCR machine with HRM capability and a 96/384 well capacity. All samples were tested in duplicate. At least 5 different normal controls for each gene were included in each run. Approximately 10 ng of DNA was amplified in a total volume of $10 \mu \mathrm{L}$ containing $400 \mathrm{nM}$ each of the relevant forward and reverse primer (NPMex12FTGATGTCTATGAAGTGTTGTGGTTCC, NPMex12RCTCTGC ATTATAAAAAGGACAGCCAG; or FLT3ex14FTGCAGAACTGCCTATT CCTAACTGA; FLT3ex14R-TTCCATAAGCTGTTGCGTTCATCAC, $4 \mathrm{mM}$ (NPM1) or $3 \mathrm{mM}$ (FLT3) $\mathrm{MgCl}_{2}$, and LightCycler 480 High-Resolution Melting Master (Roche Diagnostics). The cycling conditions were the same for both amplicons allowing them to be performed in the one run. The conditions were $95^{\circ} \mathrm{C}$ $(10 \mathrm{~min})$ and a touch down of 10 cycles of $95^{\circ} \mathrm{C}(10 \mathrm{sec})$, $65^{\circ} \mathrm{C}-55^{\circ} \mathrm{C}\left(10 \mathrm{sec}, 1^{\circ} \mathrm{C} /\right.$ step $), 72^{\circ} \mathrm{C}(30 \mathrm{sec})$ and a further 45 cycles. The melting program was $95^{\circ} \mathrm{C}(1 \mathrm{~min})$ $45^{\circ} \mathrm{C}(1 \mathrm{~min})$, then $65^{\circ} \mathrm{C}-95^{\circ} \mathrm{C}\left(5 \mathrm{sec}, 1^{\circ} \mathrm{C} / \mathrm{sec}\right)$. Thirty acquisitions were collected per ${ }^{\circ} \mathrm{C}$. Upon completion of the run (approximately 2 hours), analysis was performed using the software supplied with the LightCycler 480 . The melting curves were normalised and temperature shifted to allow samples to be directly compared. Difference plots were generated by selecting a negative control as the baseline and the fluorescence of all other samples was plotted relative to this sample. Significant differences in fluorescence were indicative of mutations. 


\section{Sequencing}

Sequencing was performed on all samples. Approximately $10 \mathrm{ng}$ of DNA was amplified in a total volume of $25 \mu \mathrm{L}$ containing $200 \mathrm{nM}$ each of M13 tagged primers, $2 \mathrm{mM}$ $\mathrm{MgCl}_{2}, 200 \mu \mathrm{M}$ each dNTPs, 0.5 units FastStart Taq (Roche Diagnostics) and $1 \times$ Buffer. The primers used were the same as stated above except that the M13 sequences 5' TGTAAAACGACGGCCAGT and 5' CAGGAAACAGCTATGACC were tagged to the forward and reverse primers respectively. The cycling conditions were $95^{\circ} \mathrm{C}(10 \mathrm{~min})$ and 45 cycles of $94^{\circ} \mathrm{C}(30 \mathrm{sec}), 64^{\circ} \mathrm{C}(30 \mathrm{sec}), 72^{\circ} \mathrm{C}(30$ sec) and $72^{\circ} \mathrm{C}$ for $10 \mathrm{~min}$. The products were checked on a $2 \%$ ethidium bromide stained agarose gel before sequencing.

\section{Competing interests}

Alex Dobrovic has received honoraria from Roche Diagnostics for speaking about HRM.

\section{Authors' contributions}

AYCT wrote the paper and performed the experiments, AD developed the assay with AYCT, co-wrote the paper and revised the paper in accordance with the reviewers' comments, DAW, DC, and JFS initiated the project, provided the specimens and assisted with writing, SJ provided specimens and performed the immunohistochemical analysis. All authors read and approved the final manuscript.

\section{Note added in proof}

After this manuscript was submitted, another report of NPM1 mutations in secondary AML has appeared [18].

\section{Acknowledgements}

This work was supported in part by a grant from Novartis Pharmaceuticals. Michelle McBean from the Diagnostic Molecular Pathology Lab, Peter MacCallum Cancer Centre extracted the DNA samples. Lee Ping Chew provided the clinical information. Prof. Bruno Falini kindly donated the antiNPM antibody (clone 376) for immunohistochemical analysis. We also thank Michael Krypuy and Chelsee Hewitt for critical reading of this manuscript.

\section{References}

I. Mrozek K, Heinonen K, Bloomfield CD: Clinical importance of cytogenetics in acute myeloid leukaemia. Best Pract Res Clin Haematol 2001, 14:19-47.

2. Farag SS, Ruppert AS, Mrozek K, Mayer RJ, Stone RM, Carroll AJ, Powell BL, Moore JO, Pettenati MJ, Koduru PR, et al: Outcome of induction and postremission therapy in younger adults with acute myeloid leukemia with normal karyotype: a cancer and leukemia group B study. I Clin Oncol 2005, 23:482-493.

3. Baldus CD, Mrozek K, Marcucci G, Bloomfield CD: Clinical outcome of de novo acute myeloid leukaemia patients with normal cytogenetics is affected by molecular genetic alterations: a concise review. Br J Haematol 2007, I37:387-400.

4. Falini B, Mecucci C, Tiacci E, Alcalay M, Rosati R, Pasqualucci L, La Starza R, Diverio D, Colombo E, Santucci A, et al.: Cytoplasmic nucleophosmin in acute myelogenous leukemia with a normal karyotype. N Engl J Med 2005, 352:254-266.

5. Boissel N, Renneville A, Biggio V, Philippe N, Thomas X, Cayuela JM, Terre C, Tigaud I, Castaigne S, Raffoux E, et al.: Prevalence, clinical profile, and prognosis of NPM mutations in AML with normal karyotype. Blood 2005, 106:3618-3620.
6. Dohner K, Schlenk RF, Habdank M, Scholl C, Rucker FG, Corbacioglu A, Bullinger L, Frohling S, Dohner H: Mutant nucleophosmin (NPMI) predicts favorable prognosis in younger adults with acute myeloid leukemia and normal cytogenetics: interaction with other gene mutations. Blood 2005, 106:3740-3746

7. Schnittger S, Schoch C, Kern W, Mecucci C, Tschulik C, Martelli MF, Haferlach T, Hiddemann W, Falini B: Nucleophosmin gene mutations are predictors of favorable prognosis in acute myelog. enous leukemia with a normal karyotype. Blood 2005, 106:3733-3739.

8. Suzuki T, Kiyoi H, Ozeki K, Tomita A, Yamaji S, Suzuki R, Kodera Y, Miyawaki S, Asou N, Kuriyama K, et al: Clinical characteristics and prognostic implications of NPMI mutations in acute myeloid leukemia. Blood 2005, 106:2854-2861.

9. Verhaak RG, Goudswaard CS, van Putten W, Bijl MA, Sanders MA Hugens W, Uitterlinden AG, Erpelinck CA, Delwel R, Lowenberg B, et al.: Mutations in nucleophosmin (NPMI) in acute myeloid leukemia (AML): association with other gene abnormalities and previously established gene expression signatures and their favorable prognostic significance. Blood 2005, 106:3747-3754

10. Thiede C, Koch S, Creutzig E, Steudel C, Illmer T, Schaich M, Ehninger G: Prevalence and prognostic impact of NPMI mutations in I 485 adult patients with acute myeloid leukemia (AML). Blood 2006, 107:40II-4020.

II. Wittwer CT, Reed GH, Gundry CN, Vandersteen JG, Pryor RJ: High-resolution genotyping by amplicon melting analysis using LCGreen. Clin Chem 2003, 49(6 Pt I):853-860.

12. Nakao M, Yokota S, Iwai T, Kaneko H, Horiike S, Kashima K, Sonoda Y, Fujimoto T, Misawa S: Internal tandem duplication of the fit3 gene found in acute myeloid leukemia. Leukemia 1996, 10:1911-1918.

13. Abu-Duhier FM, Goodeve AC, Wilson GA, Gari MA, Peake IR, Rees DC, Vandenberghe EA, Winship PR, Reilly JT: FLT3 internal tandem duplication mutations in adult acute myeloid leukaemia define a high-risk group. Br J Haematol 2000, I I I: 190-195.

14. Heiss E, Masson K, Sundberg C, Pedersen M, Sun J, Bengtsson S, Ronnstrand L: Identification of Y589 and Y599 in the juxtamembrane domain of Flt3 as ligand-induced autophosphorylation sites involved in binding of Src family kinases and the protein tyrosine phosphatase SHP2. Blood 2006, 108: $1542-1550$

15. Reindl C, Bagrintseva K, Vempati S, Schnittger S, Ellwart JW, Wenig K, Hopfner KP, Hiddemann W, Spiekermann K: Point mutations in the juxtamembrane domain of FLT3 define a new class of activating mutations in AML. Blood 2006, 107:3700-3707.

16. Vaughn CP, Elenitoba-Johnson KS: High-resolution melting analysis for detection of internal tandem duplications. J Mol Diagn 2004, 6:2II-2I6.

17. Roti G, Rosati R, Bonasso R, Gorello P, Diverio D, Martelli MF, Falini $B$, Mecucci $C$ : Denaturing high-performance liquid chromatography: a valid approach for identifying NPMI mutations in acute myeloid leukemia. J Mol Diagn 2006, 8:254-259.

18. Andersen MT, Andersen MK, Christiansen DH, Pedersen-Bjergaard J: NPMI mutations in therapy-related acute myeloid leukemia with uncharacteristic features. Leukemia 2008, 22:95I-955.

Publish with Bio Med Central and every scientist can read your work free of charge

"BioMed Central will be the most significant development for disseminating the results of biomedical research in our lifetime. "

Sir Paul Nurse, Cancer Research UK

Your research papers will be:

- available free of charge to the entire biomedical community

- peer reviewed and published immediately upon acceptance

- cited in PubMed and archived on PubMed Central

- yours - you keep the copyright
BioMedcentral 